\title{
Etnodesenvolvimento e bem viver: concepções e implicações para políticas públicas
}

\author{
Ethnodevelopment and buen vivir: conceptions and implications for public policy \\ Etnodesarrollo y buen vivir: concepciones e implicaciones para las políticas públicas
}

Recebido: 11/02/2021 | Revisado: 14/02/2021 | Aceito: 16/02/2021 | Publicado: 25/02/2021

Fernando da Cruz Souza

ORCID: https://orcid.org/0000-0002-7346-4776 Universidade Estadual Paulista "Júlio de Mesquita Filho", Brasil

E-mail: fernando.cruz@unesp.br

Ana Maria Barbosa Quiqueto

ORCID: https://orcid.org/0000-0003-1447-0858 Universidade Estadual Paulista "Júlio de Mesquita Filho", Brasil E-mail: a.quiqueto@unesp.br

Milena Botelho Azevedo Lena

ORCID: https://orcid.org/0000-0003-1228-4170 Secretaria de Comunicação da Prefeitura de Palmas-Tocantins, Brasil E-mail:milazev@gmail.com

Vilso Junior Chierentin Santi

ORCID: https://orcid.org/0000-0003-0970-6459 Universidade Federal de Roraima, Brasil E-mail: vjrsanti@gmail.com

Nelson Russo de Moraes

ORCID: https://orcid.org/0000-0003-0159-9433 Universidade Estadual Paulista "Júlio de Mesquita Filho", Brasil E-mail: nelson.russo@unesp.br

\section{Resumo}

Questionamentos radicais sobre as ideias vinculadas à noção de desenvolvimento, tais como, crescimento, progresso, reforma de mercado, extrativismo, aumento desmedido de consumo material individual, etc., confluem para desenvolvimentos alternativos ou alternativas à própria ideia de desenvolvimento. Diante disso, esse artigo discutiu as diferenças entre as concepções de etnodesenvolvimento e bem viver indígena em sua interface com as políticas públicas por meio de uma revisão narrativa de literatura. Os resultados apontam que a ideia de desenvolvimento tem se transformado desde a modernização e crescimento econômico para perspectivas mais críticas ou negadoras do paradigma capitalista de desenvolvimento. $\mathrm{O}$ etnodesenvolvimento, embora centralize a questão étnica, histórica e cultural nos processos de desenvolvimento, ainda o faz com a finalidade de eficiência econômica. Já o bem viver busca a plenitude e o equilíbrio entre os povos, a natureza e a metafísica, o que o coloca como uma alternativa ao desenvolvimento, uma vez que não se ampara na lógica judaico-cristã, antropocêntrica e racional-científica. Concluise que o etnodesenvolvimento, pela perspectiva indígena, parece ser menos interessante como projeto de desenvolvimento e que o bem viver, embora tenha sido reconhecido constitucionalmente na Bolívia e no Equador, tem implantação sempre conflituosa devido à colonização capitalista nos modos de pensar o tempo, o espaço, a economia, as relações sociais, a natureza, a sociedade e, por isso, as políticas públicas.

Palavras-chave: Desenvolvimento alternativo; Alternativa ao desenvolvimento; Sumak kawsay; Suma qamaña; Análise de políticas públicas.

\footnotetext{
Abstract

Radical questions about the ideas linked to the notion of development, such as, growth, progress, market reform, extractivism, excessive increase in individual material consumption, etc., converge to alternative developments or alternatives to the idea of development itself. That said, this article discussed the differences between the concepts of ethnodevelopment and indigenous buen vivir in its interface with public policy through a conventional literature review. The results show that the idea of development has been transformed from modernization and economic growth to more critical or negative perspectives of the capitalist development paradigm. Ethnodevelopment, while focusing on the ethnic, historical and cultural issues in development processes, still does so for the purpose of economic efficiency. Buen vivir, on the other hand, seeks fullness and balance between peoples, nature and metaphysics, which puts it as an alternative to development, since it is not supported by Judaic-Christian, anthropocentric and rational-scientific logic. It is concluded that ethnodevelopment, from the indigenous perspective, seems to be less interesting as a development project and that buen vivir, although it has been constitutionally recognized in Bolivia and Ecuador, has always been in conflict due to capitalist colonization in ways of thinking about time, space, economics, social relations, nature, society and, therefore, public policy.
} 
Keywords: Alternative development; Alternative to development; Sumak kawsay; Suma qamaña; Public policy analysis.

\begin{abstract}
Resumen
Cuestiones radicales sobre las ideas ligadas a la noción de desarrollo, tales como, crecimiento, progreso, reforma de mercado, extracción, incremento excesivo del consumo material individual, etc., convergen hacia desarrollos alternativos o alternativas a la propia idea de desarrollo. Ante esto, este artículo discutió las diferencias entre los conceptos de etnodesarrollo y el buen vivir indígena en su interfaz con las políticas públicas a través de una revisión de la literatura convencional. Los resultados muestran que la idea de desarrollo se ha transformado desde la modernización y el crecimiento económico hacia perspectivas más críticas o negativas del paradigma de desarrollo capitalista. El etnodesarrollo, si bien centraliza la cuestión étnica, histórica y cultural en los procesos de desarrollo, todavía lo hace con el propósito de la eficiencia económica. La buena vida, en cambio, busca la plenitud y el equilibrio entre los pueblos, la naturaleza y la metafísica, lo que la sitúa como una alternativa al desarrollo, ya que no se sustenta en la lógica judaico-cristiana, antropocéntrica y racional-científica. Se concluye que el etnodesarrollo, desde la perspectiva indígena, parece ser menos interesante como proyecto de desarrollo y que el buen vivir, aunque ha sido reconocido constitucionalmente en Bolivia y Ecuador, siempre ha estado en conflicto por la colonización capitalista en las formas de pensar el tiempo, espacio, economía, relaciones sociales, naturaleza, sociedad y, por tanto, políticas públicas.
\end{abstract}

Palabras clave: Desarrollo alternativo; Alternativa al desarrollo; Sumak kawsay; Suma qamaña; Análisis de políticas públicas.

\title{
1. Introdução
}

O mito neoliberal do capitalismo autorregulador, que substitui o welfare state, cuja ideia era a do pleno emprego, do protagonismo estatal na economia e do não desperdício de recursos, são ambos paradigmas ultrapassados que impõem a necessidade de que se criem soluções inovadoras quanto ao desenvolvimento desejado pela sociedade. Nesse sentido, não se pode aceitar o crescimento econômico socialmente benigno, porém ambientalmente negativo, assim como não se pode aceitar o crescimento econômico ambientalmente benigno, mas que relega grandes contingentes da sociedade à situação de pobreza (Sachs, 2009).

Portanto, a sociedade se encontra diante da necessidade de construir um desenvolvimento sustentável, o qual não compreenda a natureza apenas como uma função de utilidade para o ser humano, mas como um sujeito de valores. Em outras palavras, o comportamento respeitoso ao meio ambiente e à sociedade, se se pensa na sobrevida da espécie humana, deve se contrapor aos projetos produtivos exclusivamente utilitaristas. Disso decorre a necessidade de reflexão sobre os problemas éticos envolvidos nas atividades daqueles que desenham políticas públicas de desenvolvimento, bem como sobre suas concepções da relação sociedade-natureza (Gudynas, 2004).

Sen (2010) defende que o desenvolvimento não se limita apenas aos indicadores de renda. Pelo contrário, segundo o autor, o desenvolvimento deve se pautar pela melhoria de vida e pelo aumento das liberdades de que desfrutam as pessoas, a fim de perseguirem os objetivos que valorizam, de modo rico e desimpedido, tornando-se seres sociais completos, capazes de atender suas vontades, interagir com o mundo e influenciá-lo. Isso não significa que a riqueza seja desprezada, já que essa colabora no alcance de liberdades substantivas, mas que é necessário se perguntar: quais as razões de se buscar mais riquezas, do que dependem, o que se pode fazer com mais riqueza? Trata-se de perguntas importantes justamente porque a riqueza é limitada como fonte de influência na vida das pessoas (Sen, 2010).

Nesse sentido, Florit (2016, p. 257) indica que "Os processos de desenvolvimento expressam sistemas de relações sociais, muitas vezes conflitantes, que se consolidam em ordens econômicas e políticas mais ou menos duradouras, consagradas, protegidas e reproduzidas a partir do Estado ou com forte influência deste”. Isso significa que os padrões do desenvolvimento dimensionam práticas rotineiras, as quais se tornam condicionantes para outras práticas, tal que as trajetórias do desenvolvimento, em sua historicidade, resultam em combinações e dosagens de importâncias diversas dadas às concepções de crescimento dos diversos atores do mercado e da sociedade civil, os quais, por sua vez, mobilizam forças e poder simbólico 
a fim de legitimar noções normativo-prescritivas do desenvolvimento que defendem (Florit, 2016).

As mobilizações de diferentes atores sociais em torno de concepções de desenvolvimento ensejaram questionamentos radicais sobre as ideias vinculadas a esse, tais como, crescimento, progresso, reforma de mercado, extrativismo, aumento desmedido de consumo material individual etc., confluindo para uma alternativa à própria ideia de desenvolvimento. Este é o caso das análises com embasamento nos saberes e movimentos indígenas, cujo sentido é ir além dos saberes ocidentais, criticando a modernidade, marcadamente europeia, e construindo alternativas de/ao desenvolvimento (Escobar, 2014).

Uma primeira teorização nesse sentido surge com Stavenhagen (2013), antropólogo e sociólogo, o qual propõe o etnodesenvolvimento, definido como um desenvolvimento alternativo que contempla opções retificantes, reparadoras ou modificadores do desenvolvimento contemporâneo sem alterar a base conceitual de crescimento e de apropriação da natureza. No etnodesenvolvimento, uma etnia autóctone, tribal ou de outra natureza, controla suas próprias terras, recursos, organização social e cultura, tendo liberdade para estabelecer seus interesses perante o Estado (Stavenhagen, 2013).

Por outro lado, surge a alternativa ao desenvolvimento, a qual contempla a perspectiva de mudança social e a configuração do Estado para garantir condições elementares de reprodução do modo de vida da população indígena, modo esse ausente de riscos à regeneração da biodiversidade natural e cultural. A gestação dessa alternativa ao desenvolvimento, chamada de Bem Viver, se dá entre os intelectuais indígenas e permeia a esfera política no Equador e na Bolívia, onde a maioria da população é aborígene. O Bem Viver inclui uma concepção do universal como realidade plural, na qual são interdependentes a sociedade, o meio ambiente e a metafísica (Vanhulst \& Beling, 2013; Torres-Solis \& Ramírez-Valverde, 2019).

Diante disso, este trabalho se debruça sobre alternativas de desenvolvimento étnico-sensíveis, com o objetivo geral de discutir as diferenças entre as concepções de etnodesenvolvimento e bem viver indígena em sua interface com as políticas públicas, objetivo o qual foi desdobrado nos seguintes objetivos específicos: 1) Estabelecer a relação entre desenvolvimento e políticas públicas; 2) Conceituar o etnodesenvolvimento e o bem viver indígena; e 3) Identificar as implicações do etnodesenvolvimento e do bem viver nas políticas públicas.

A pesquisa sobre tais objetivos encontra justificação na necessidade de ampliação dos conhecimentos sobre os povos indígenas, cuja identificação como sujeitos sociais coletivos implica em direitos territoriais e autoconsciência cultural, resguardados por convenções internacionais e dispositivos jurídicos nacionais, os quais devem passar a constar em processos de desenvolvimento etnicamente sensíveis como imperativo ético na defesa da dignidade da pessoa humana (Almeida, 2007).

\section{Metodologia}

Quanto à abordagem, esta pesquisa pode classificada como qualitativa, uma vez que busca interpretações sobre os fenômenos da política pública em interface com alternativas de desenvolvimento étnico-sensíveis (Pereira et al., 2018). Além disso, apresenta caráter exploratório, dado que sua finalidade é o esclarecimento de conceitos e ideias referentes ao "etnodesenvolvimento", "bem viver" e "política pública" (Gil, 2002).

A técnica utilizada para o alcance do objetivo da pesquisa foi a revisão narrativa de literatura, a qual busca descrever e avaliar materiais produzidos sobre os assuntos pesquisados. Tanto Creswell (2007) como Ferrari (2015) indicam a utilização de um modelo de protocolo para a revisão narrativa. Na Figura 1, as etapas da revisão de literatura, segundo esses autores, são explicitadas. 
Figura 1. Etapas da revisão de literatura.

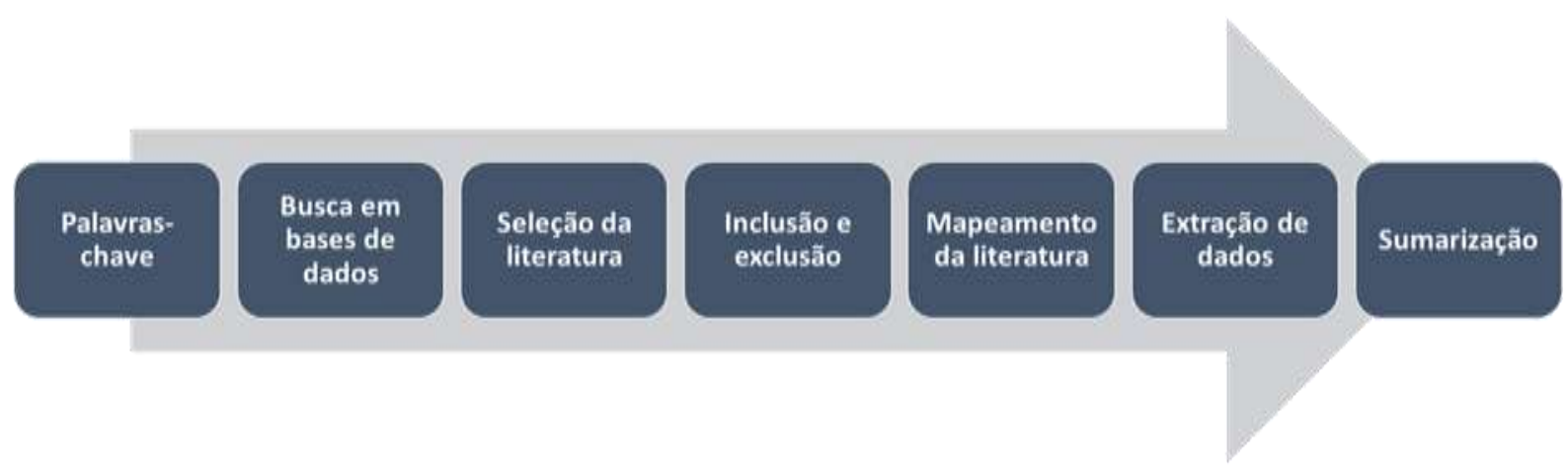

Fonte: Adaptado de Creswell (2007) e Ferrari (2015).

Para cada uma das etapas presentes na Figura 1, são registradas as decisões tomadas nesta revisão.

Na primeira etapa, foram escolhidas as palavras-chave "etnodesenvolvimento", "bem viver" e política pública, assim como alguns sinônimos para o termo bem viver, entre eles sumak kawsay e suma qamaña, além da tradução de todos os termos tanto para o inglês como para o espanhol.

$\mathrm{Na}$ segunda etapa, a pesquisa com tais palavras-chave foi executada na base de dados acadêmicos Scielo e no metabuscador Google Scholar, no mês de novembro de 2020. Além disso, foram utilizadas literaturas previamente conhecidas pelos autores juntamente com literaturas indicadas por especialistas sobre tais assuntos, as quais funcionaram como leituras de escopo para a aproximação com os temas da pesquisa.

Os tipos de literaturas selecionadas para apreciação após a busca (terceira etapa) foram livros, capítulos de livros, artigos em periódicos e relatórios de agências de pesquisa. Concomitantemente, foram selecionados apenas textos em língua portuguesa, espanhola ou inglesa.

Para decidir sobre a inclusão ou exclusão dos textos obtidos na etapa de busca (quarta etapa), fez-se a leitura do título, resumo e palavras-chave, como primeiro critério, e a leitura da introdução e conclusão, como segundo critério. Materiais não excluídos após a verificação de ambos os critérios foram lidos por completo e utilizados na revisão, em caso de atendimento aos objetivos da pesquisa.

Em função do fornecimento de conceituações e críticas sobre os temas pesquisados e suas interrelações, foram mapeadas as literaturas coletadas (quinta etapa). Isso permitiu a extração de dados segundo os objetivos específicos (sexta etapa), os quais, posteriormente, foram sumarizados em argumentos e citações presentes neste artigo (sétima etapa).

\section{Resultados e Discussão}

\subsection{Relação entre desenvolvimento e políticas públicas}

Uma forma propositalmente genérica de se compreender desenvolvimento é elaborada por Castro e Oliveira (2014, p. 22) como "[...] a capacidade de determinada sociedade superar os entraves à realização de suas potencialidades [podendo] ser abordado em múltiplas dimensões, sempre levando em consideração as especificidades históricas e sociais [...]". Heidemann (2014, p. 29), por seu turno, afirma que "[...] o desenvolvimento de uma sociedade, em nosso tempo, resulta de decisões formuladas e implementadas por governos de estados (em suas instâncias nacionais, subnacionais e supranacionais), em conjunto com as demais forças da sociedade [...]”. No entanto, o próprio autor deriva de tal definição algumas perguntas essenciais: "[...] desenvolve-se o que, para quem, com que benefício e a que custo? Que dimensões do ser humano são atendidas ou satisfeitas por um processo de desenvolvimento?" (Heidemann, 2014, p. 30).

A fim de responder tais perguntas, é interessante revisitar as transformações na compreensão do conceito de 
desenvolvimento ao longo do tempo. Escobar (2014) identifica três grandes fases contrastantes do desenvolvimento na sociologia do conhecimento entre os anos de 1951 a 2000, as quais são expressas no Quadro 1.

Quadro 1. Genealogia do desenvolvimento (1951-2000).

\begin{tabular}{|c|c|}
\hline Fase e período & Características principais \\
\hline $\begin{array}{l}\text { Modernização } \\
(1950-1970)\end{array}$ & $\begin{array}{l}\text { Baseada na teoria liberal, teóricos e elites mundiais acreditavam que o capital, a ciência e a tecnologia, se } \\
\text { aplicados segundo as recomendações de instituições como o Banco Mundial e universidades de países } \\
\text { centrais, levariam sociedades tradicionais à modernização - modernidade significando riqueza, } \\
\text { racionalidade e felicidade, os quais seriam advindos do crescimento econômico. }\end{array}$ \\
\hline $\begin{array}{l}\text { Teoria da } \\
\text { dependência } \\
\text { (1960-1970) }\end{array}$ & $\begin{array}{l}\text { Baseada em teorias marxistas, acreditava-se no subdesenvolvimento como decorrente de duas causas } \\
\text { principais: 1) a dependência econômica externa por parte dos países periféricos em relação aos países } \\
\text { centrais; e 2) a exploração social interna de cunho classista, não a ausência de capital, tecnologia e valores, } \\
\text { como afirmava a fase anterior. Em outras palavras, o problema residia no capitalismo, não no } \\
\text { desenvolvimento, de modo que o sucesso do desenvolvimento residiria na transformação do capitalismo } \\
\text { em socialdemocracia. }\end{array}$ \\
\hline $\begin{array}{l}\text { Críticas culturais } \\
(1990-2000)\end{array}$ & $\begin{array}{l}\text { Baseada em teorias pós-estruturalistas, assinala críticas culturais por todo o mundo, questionando o próprio } \\
\text { conceito de desenvolvimento, compreendendo-o como um discurso de dominação da produção cultural, } \\
\text { social, econômica e política do Terceiro Mundo, discurso o qual representa/inventa a África, a Ásia e a } \\
\text { América Latina como regiões subdesenvolvidas, a fim de moldar a realidade de tais países. }\end{array}$ \\
\hline
\end{tabular}

Fonte: Escobar (2014).

Ainda buscando responder as perguntas de Heidemann, vê-se que concepções mais modernas de desenvolvimento superam, entre outras coisas, a correspondência entre esse e o progresso ou crescimento econômico puro e simples. Este é o caso da teoria de desenvolvimento como liberdade, na qual se fazem presentes atributos de justiça socioambiental.

Nesta concepção, Sen (2010, p. 16-17) evidencia que para acontecer o desenvolvimento, é necessária a remoção das principais fontes de privação da liberdade, a saber, “[...] pobreza e tirania, carência de oportunidades econômicas e destituição social sistemática, negligência dos serviços públicos e intolerância ou interferência excessiva de Estados repressivos”, as quais representam a subtração substantiva de liberdades, como a de saciar a fome, estar adequadamente nutrido, ter acesso a medicamentos, vestimentas e moradia adequados, à saneamento básico, etc. Ainda, tais privações poderiam representar a falta de assistência social e serviços públicos, tais como programas epidemiológicos, de assistência médica, de educação, de instituições de manutenção da paz e ordem e, até mesmo, a supressão de liberdades políticas e civis por regimes autoritários (Sen, 2010).

Sen (2010, p. 10) diz que "A expansão da liberdade é [...] o principal fim e o meio do desenvolvimento", de modo que a eliminação das referidas fontes de privação ampliaria as escolhas e as oportunidades das pessoas no exercício de seu poder de agência. Além disso, o autor adiciona que a liberdade tem eficácia instrumental no desenvolvimento porque tem encadeamentos causais. Por exemplo, liberdades econômicas e políticas promovem reforço entre si; educação e assistência médica podem ser complementadas por políticas públicas, somando-se às oportunidades individuais de participação econômica e política, o que favorece a superação de privações (Sen, 2010). Algumas das liberdades instrumentais cruciais citadas pelo 
autor são resumidas no Quadro 2:

Quadro 2. Tipos de liberdades instrumentais.

\begin{tabular}{|c|c|}
\hline $\begin{array}{c}\text { Liberdades } \\
\text { instrumentais }\end{array}$ & Definição \\
\hline $\begin{array}{l}\text { Liberdades } \\
\text { políticas }\end{array}$ & $\begin{array}{l}\text { Podem também ser chamadas de direitos civis e se relacionam à possibilidade que as pessoas têm de } \\
\text { decidir quem governa e a partir de quais princípios. Inclui as possibilidades de fiscalização e crítica ao } \\
\text { governo; liberdade de expressão política e ausência de censura sobre a imprensa; liberdade de opção entre } \\
\text { partidos políticos; e liberdades democráticas mais amplas, tais como, diálogo político, dissensão e crítica, } \\
\text { direito ao voto para selecionar membros do executivo e do legislativo. }\end{array}$ \\
\hline $\begin{array}{l}\text { Facilidades } \\
\text { econômicas }\end{array}$ & $\begin{array}{l}\text { Diz respeito ao consumo, produção e troca de recursos econômicos realizados pelos indivíduos, os quais } \\
\text { dependem da quantidade de recursos econômicos que aqueles têm a sua disposição, das condições de troca } \\
\text { estabelecidas pelo mercado, do desenvolvimento desse e dos preços relativos. A maneira como a renda é } \\
\text { distribuída na sociedade faz diferença, assim como o acesso ao crédito para todos os agentes econômicos. }\end{array}$ \\
\hline $\begin{array}{l}\text { Oportunidades } \\
\text { sociais }\end{array}$ & $\begin{array}{l}\text { Se refere à disponibilidade de educação, saúde, etc., pois os bens e serviços associados a tais áreas exercem } \\
\text { influências na liberdade substantiva do indivíduo de viver melhor. No que tange à saúde, por exemplo, ao } \\
\text { levar uma vida saudável, ao não ser vítima de doenças evitáveis ou morte prematura, tem-se melhores } \\
\text { condições de participação em atividades políticas e econômicas. Quanto à educação, o analfabetismo é } \\
\text { exemplo de grande barreira para inserção em atividades econômicas ou para a participação na vida política, } \\
\text { pelo impedimento da comunicação por escrito. }\end{array}$ \\
\hline $\begin{array}{l}\text { Garantias de } \\
\text { transparência }\end{array}$ & $\begin{array}{l}\text { Está relacionada com a salvaguarda da clareza e do dessegredo, podendo inibir a corrupção, a } \\
\text { irresponsabilidade financeira e as transações ilícitas. }\end{array}$ \\
\hline $\begin{array}{l}\text { Segurança } \\
\text { protetora }\end{array}$ & $\begin{array}{l}\text { Trata-se de uma rede de segurança social cuja função é impedir que, devido a mudanças materiais que } \\
\text { possam gerar grandes privações, as pessoas entrem em situação de miséria, fome e morte. Há, nesse caso, } \\
\text { políticas fixas como o seguro desemprego, a complementação de renda para pessoas extremamente pobres, } \\
\text { a distribuição de alimentos e empregos públicos de emergência para gerar renda àqueles que necessitem. }\end{array}$ \\
\hline
\end{tabular}

Fonte: Sen (2010).

Valendo-se também da abordagem das capacidades de Sen, as liberdades instrumentais do desenvolvimento têm sido utilizadas juntamente com os fundamentos de Sumak Kawsay e de Suma Qamaña, com origem, respectivamente, entre os povos indígenas Kichwa e Aymara. Tais expressões podem ser traduzidas como bem viver e viver bem e se relacionam a um estilo de vida de complementaridade entre os povos, as forças da natureza e o sobrenatural. Nestes conceitos, é central que existam condições materiais e espirituais de levar a vida em harmonia com a natureza, incluindo condições objetivas, como riqueza, poder, comodidades, tempo livre, acesso a serviços de saúde e educação, mas também condições subjetivas, como prazer, felicidade, desejos, anseios, planos de vida, etc. Em outras palavras, o modo de vida indígena é holístico e o bem-estar dele advindo requer equilíbrio territorial com o ecossistema, fundando-se nos seguintes eixos: base natural de recursos participantes da vida indígena; reprodução material da sociedade indígena por meio dos conhecimentos tradicionais de sujeitos 
indígenas; e reprodução cultural, individual e coletiva que garanta a vida (Acosta et al., 2020).

Após o período de críticas culturais ao desenvolvimento, há o surgimento do conceito pós-desenvolvimento, delimitado pelo período entre 1991 e 2010. Em primeiro lugar, o pós-desenvolvimento compreende uma tentativa de deslocar o desenvolvimento, suas representações e discursos da posição central que ocupavam, podendo, assim, abrir espaço para outras formas de descrever a realidade, não eivadas de premissas e experiências desenvolvimentistas. Em segundo lugar, o pósdesenvolvimento considera possível o fim do desenvolvimento e suas alternativas (participativo, sustentável, humano, etc.), consideradas partes de um mesmo universo discursivo. Em terceiro lugar, o pós-desenvolvimento tem como objetivo transformar a configuração de poder e conhecimento estabelecida pelo desenvolvimento, propondo que as alternativas possíveis de práticas e conhecimentos podem emergir de movimentos sociais. É a partir dessa nova noção que surgem conceitos como o bem viver, sobre o qual são feitas discussões na seção posterior (Escobar, 2014).

Quaisquer que sejam os processos de desenvolvimento, sua consolidação e permanência em horizontes temporais mais longos são frutos da ação do Estado, os quais estabelecem constituições e instituições em torno de projetos de desenvolvimento que, por sua vez, resultam de disputas políticas entre os diferentes segmentos da sociedade. Tais projetos são fontes de diferentes direitos e deveres aos cidadãos e se concretizam por meio de políticas públicas (Castro \& Oliveira, 2019), por isso, faz-se necessário compreender esse termo.

A definição funcional de política pública, promovida por Howlett; Ramesh e Perl (2013), se refere a um processo em que atores, com suas respectivas restrições, tentam compatibilizar objetivos e meios políticos a fim de resolver problemas de forma aplicada. Já a definição fornecida por Secchi $(2013$, p. 1) informa que a política pública trata do "[...] conteúdo concreto e do conteúdo simbólico de decisões políticas, e do processo de construção e atuação dessas decisões". Enquanto Rua (1998) destaca que a política pública (policy) é resultado da atividade política e envolve, em geral, mais do que uma decisão, além de requerer ações estratégicas a fim de implementar a decisão tomada. Rua afirma, ainda, que o status público da política pública - não privado ou coletivo - se dá não pelo tamanho da população sobre a qual essa incide, mas pelo caráter imperativo que carrega (Rua, 1998).

Importa dizer que, se por um lado, nenhuma dessas definições de política pública são concorrentes, pelo contrário, são complementares, por outro, compreensões distintas sobre o fenômeno da política pública levarão a diferentes formas de conceber problemas e soluções. Nos processos da política pública, o problema, definido como a diferença entre uma situação atual (status quo) e a situação ideal possível, ocupa espaço importante de análise, pois se uma política pública tem como objetivo resolver um problema público, determinadas percepções do problema ensejam determinadas formulações de soluções (Secchi, 2016), o que explica a grande quantidade de modelos de análise de decisões político-administrativas, alguns dos quais são sumarizados no Quadro 3. 
Quadro 3. Modelos conceituais para analisar políticas públicas.

\begin{tabular}{|c|c|}
\hline Modelo & Definição \\
\hline Institucionalismo & $\begin{array}{l}\text { Compreende que as atividades políticas giram em torno de instituições governamentais cujos padrões de } \\
\text { comportamento entre indivíduos e grupos tendem a persistir ao longo do tempo, tais como, Congresso, } \\
\text { presidência, tribunais, estados, municípios, etc. As instituições fornecem às políticas públicas: legitimidade, } \\
\text { pois geram obrigações legais; universalidade, pois se referem a todos na sociedade; e monopólio da } \\
\text { coerção, pois somente o Estado pode punir os violadores de suas políticas. Além disso, as instituições } \\
\text { podem afetar o conteúdo das políticas públicas porque estão em condições de facilitar certas } \\
\text { consequências, favorecer certos interesses, indivíduos ou grupos que tenham maior acesso ao poder } \\
\text { governamental. }\end{array}$ \\
\hline $\begin{array}{l}\text { Processos de } \\
\text { gestão }\end{array}$ & $\begin{array}{l}\text { São agrupadas diversas atividades com base na relação que têm com a política pública, tais como: 1) } \\
\text { Identificação do problema (manifestação de demandas); 2) Montagem da agenda (escolha de questões e } \\
\text { problemas a serem tratados); 3) Formulação (propostas de políticas para resolver questões e problemas); 4) } \\
\text { Legitimação (articulação de apoio político a uma proposta de política pública, a fim de transformá-la em } \\
\text { lei); 5) Implementação (organização da burocracia, provisão de serviços, pagamentos e impostos); e 6) } \\
\text { Avaliação (estudo dos programas, suas saídas, impactos sobre público-alvo e proposição de mudanças). }\end{array}$ \\
\hline $\begin{array}{l}\text { Grupos de } \\
\text { interesse }\end{array}$ & $\begin{array}{l}\text { Indivíduos com interesses comuns se unem, formal ou informalmente, para apresentar suas demandas ao } \\
\text { governo. O indivíduo só é importante quando age em nome do grupo. A política se define pela luta entre os } \\
\text { grupos para influenciar a política pública e, neste ponto, o papel do político é: estabelecer as regras do jogo } \\
\text { para a disputa entre grupos; negociar acordos que equilibram interesses entre os grupos; oficializá-los em } \\
\text { forma de políticas públicas; e cumpri-los. A influência dos grupos se dá em função de seu tamanho, } \\
\text { riqueza, poder organizacional, liderança, acesso aos formuladores de decisão e coesão interna. Políticos } \\
\text { formam coalizões majoritárias de grupos, coalizões cujos tamanhos dependem da clientela a que atendem, } \\
\text { sendo um exemplo os partidos. O equilíbrio do sistema é mantido por várias forças, como pelo apoio às } \\
\text { regras do jogo vigentes (constituição), pela filiação simultânea a vários grupos e pelos freios e contrapesos. }\end{array}$ \\
\hline Elitismo & $\begin{array}{l}\text { Sugere que o povo é apático e mal informado sobre as políticas públicas e que a elite molda a opinião das } \\
\text { massas sobre assuntos políticos, tal que as políticas públicas traduzem as preferências de elites e os } \\
\text { administradores e funcionários públicos as implementam num fluxo de cima para baixo. São características } \\
\text { do elitismo: poucos têm muito poder e alocam valores para a sociedade; as elites pertencem à classe } \\
\text { socioeconômica superior; pode haver transição lenta e gradual de pessoas não pertencentes à elite para esta } \\
\text { classe a fim de manter a estabilidade; há consenso entre as elites sobre alguns valores sociais básicos, como } \\
\text { propriedade privada, liberdade individual, tamanho do governo, etc.; as mudanças nas políticas públicas } \\
\text { são incrementais; e as elites influenciam mais as massas do que o contrário. As elites não são contra o bem- } \\
\text { estar das massas, mas estão no comando dessa, enquanto instituições, como eleições e partidos, têm valor } \\
\text { apenas simbólico, por darem um papel discernível com o qual as massas se identificam sem que essas } \\
\text { tenham, de fato, influência sobre as deliberações da elite. }\end{array}$ \\
\hline
\end{tabular}




\begin{tabular}{|c|c|}
\hline Racionalismo & $\begin{array}{l}\text { Considera racional a política pública cujos ganhos sociais sejam maiores do que os custos, o que envolve } \\
\text { valores políticos e sociais, não apenas valores monetários. A seleção de uma política racional segue os } \\
\text { seguintes passos: 1) Conhecer as preferências da sociedade e os pesos dessas; 2) Conhecer todas as } \\
\text { propostas de políticas; 3) Conhecer as consequência de cada proposta; 4) Calcular o custo/benefício de } \\
\text { cada proposta; e 5) Selecionar a proposta mais eficiente. Tais etapas pressupõem que as preferências } \\
\text { valorativas da sociedade podem ser conhecidas, que há informações sobre as propostas, que há capacidade } \\
\text { preditiva pelo pessoal especializado e que há um sistema de tomada de decisão. Este modelo pressupõe, } \\
\text { ainda, o máximo ganho social, por isso, é usado para ponderar o tamanho do governo, de modo que o gasto } \\
\text { deva crescer até o máximo ganho líquido. Algumas barreiras do modelo são: os benefícios das políticas não } \\
\text { se destinam à sociedade como um todo, mas a grupos ou indivíduos, por isso, não podem ser comparados; } \\
\text { formuladores de políticas buscam recompensas de poder, status, reeleição, dinheiro, não tomam decisões } \\
\text { com objetivos exclusivamente societários; propostas de políticas rejeitadas não voltam a ser analisadas; } \\
\text { informações têm grande custo monetário e de tempo para a coleta e podem não estar disponíveis; a } \\
\text { capacidade preditiva das ciências ainda não é suficiente para a avaliação de todos os custos e benefícios das } \\
\text { propostas; há carência de conhecimento especializado; a incerteza a respeito de consequências afasta os } \\
\text { legisladores de políticas muito diferentes das anteriores; e, por sua natureza fragmentária, a formulação de } \\
\text { políticas é difícil de ser coordenada. }\end{array}$ \\
\hline Incrementalismo & $\begin{array}{l}\text { A política pública é entendida como continuidade de governos anteriores e sofre apenas mudanças } \\
\text { incrementais, pois restrições de tempo, informação e custos impedem a avaliação nos moldes racionalistas. } \\
\text { Assim, parte-se de programas existentes, sobre os quais são realizadas modificações, de tal forma que é } \\
\text { emprestada, tacitamente, a legitimidade advinda do programa anterior, uma vez que não se conhecem as } \\
\text { consequências de políticas diferentes e novas. Além disso, sunk costs de natureza material, psicológica, de } \\
\text { práticas administrativas ou de estrutura organizacional contraindicam mudanças radicais, tornando o } \\
\text { incrementalismo conveniente frente aos atores envolvidos na política pública porque esse diminui as } \\
\text { chances de conflitos. Deve-se considerar também que os seres humanos escolhem as alternativas mais } \\
\text { familiares e cujo funcionamento já se mostre eficaz, satisfazendo, assim, suas demandas particulares de } \\
\text { pragmatismo. }\end{array}$ \\
\hline Opção pública & $\begin{array}{l}\text { A teoria da ação pública defende que atores políticos (eleitores, contribuintes, candidatos, legisladores, } \\
\text { burocratas, grupos de interesse, partidos, burocracias e governos) buscam a maximização dos benefícios } \\
\text { obtidos tanto no âmbito do mercado como no âmbito da política, por isso, tais atores se associam } \\
\text { politicamente a fim de alcançarem benefícios mútuos mediante contratos, de sorte que, mesmo se o ponto } \\
\text { de partida for o autointeresse, são gerados benefícios bilaterais oriundos da tomada de decisão coletiva. Um } \\
\text { exemplo expressivo é o do contrato social, no qual as pessoas aceitam leis e financiam o Estado que, por } \\
\text { sua vez, protege suas vidas, liberdades e propriedades. Esta teoria reconhece que: 1) o governo deve ofertar } \\
\text { bens públicos, os quais, devido às falhas de mercado, não podem ser oferecidos privadamente, pois seus } \\
\text { custos excedem o valor de compra; 2) o governo deve compensar externalidades - custos impostos à } \\
\text { sociedade como um todo a partir de atividades de indivíduos, empresas ou do próprio governo -, por meio } \\
\text { de regulamentação e penalidades; } 3 \text { ) partidos e políticos têm dificuldades de apresentar propostas } \\
\text { específicas, porque buscam maximizar a quantidade de votos, portanto, tendendo ao centro em suas }\end{array}$ \\
\hline
\end{tabular}




\begin{tabular}{|c|c|}
\hline & $\begin{array}{l}\text { opiniões, com exceção dos ideólogos; 4) os interesses de políticos e burocratas são diferentes dos interesses } \\
\text { dos eleitores, pois, enquanto os primeiros buscam reeleição, contribuições de campanha, maiores } \\
\text { orçamentos para entidades governamentais, mais autoridade e prestígio, a preferência eleitoral é difícil de } \\
\text { ser verificada; e 5) os políticos e burocratas expandem benefícios de programas governamentais (subsídios, } \\
\text { privilégios, proteção), por ser difícil verificar as preferências eleitorais, atingindo mais alguns grupos do } \\
\text { que outros, e subestimando os custos, que são distribuídos entre todos, o que leva ao excesso de bens e } \\
\text { serviços públicos e à tributação excessiva; e 6) grupos de pressão menores, mais homogêneos e bem- } \\
\text { organizados concentram mais benefícios governamentais. }\end{array}$ \\
\hline Sistêmico & $\begin{array}{l}\text { Concebe que condições ou circunstâncias do meio ambiente, tais como demandas (de indivíduos ou grupos } \\
\text { que buscam influenciar a política pública) e apoios (aceitação das decisões políticas) são entradas. Estas } \\
\text { são processadas por um conjunto de estruturas e processos interligados, o sistema político, formado por } \\
\text { instituições e atividades na sociedade, as quais devem promover acordos e fazê-los ser cumpridos pelas } \\
\text { partes interessadas. De tal processamento resultam as políticas públicas, saídas de alocação de valores } \\
\text { oficiais. Este modelo considera que as políticas públicas podem modificar o ambiente, suas demandas e o } \\
\text { próprio caráter do sistema político; e que sua preservação é função de políticas públicas satisfatórias, da } \\
\text { submissão às próprias vinculações internas, e do uso ou ameaça de uso da coerção. }\end{array}$ \\
\hline
\end{tabular}

Fonte: Dye (2014).

Os modelos apresentados têm a finalidade de evidenciar quem ganha o quê, quando e como, podendo revelar como as políticas públicas afetam a vida das pessoas, como regulam comportamentos e conflitos, como organizam mercados e burocracias, como distribuem benefícios e serviços aos cidadãos. Isso é importante porque o Estado obtém recursos junto à sociedade, por meio de tributos diversos, a fim de promover políticas públicas, mas faz opção apenas por algumas políticas, e não outras, e age ou deixa de agir em situações consideradas importantes, isto é, suas ações ou inação têm determinadas causas e consequências sobre as quais são necessárias investigações (Rodrigues, 2015).

\subsection{Conceitos de etnodesenvolvimento e bem viver indígena}

Com respeito ao etnodesenvolvimento, Verdum (2002) afirma que o conceito surgiu como uma alternativa crítica ao desenvolvimentismo etnocida cujo entendimento sobre os povos indígenas e tradicionais era o de que obstaculizavam o progresso. Para Batalla (1982, p. 133), considerado por Verdum um precursor desta vertente, o etnodesenvolvimento é “[...] o exercício da capacidade social de um povo para construir seu futuro, aproveitando para isso os ensinamentos de sua experiência histórica e os recursos reais e potenciais de sua cultura, de acordo com um projeto que se define segundo seus próprios valores e aspirações".

Stavenhagen (2013, p. 85) complementa Batalla dizendo que o etnodesenvolvimento indígena latino-americano "[...] significa a completa reversão das políticas públicas indigenistas [...] [e que] Um novo movimento social indígena militante surgiu e demanda reafirmação de seus valores culturais e a reavaliação dos indígenas na estrutura social”. Consoante a isso, Verdum (2002) sublinha que, com a Constituição Federal de 1988, são reconhecidos os direitos à organização e representação indígena, tornando possível que passem a defender e reivindicar direitos referentes ao território, à saúde, à educação e à manifestação.

Em termos práticos, para Azanha (2002), o etnodesenvolvimento estaria condicionado aos seguintes elementos: resolução preliminar das questões de segurança territorial; fruição exclusiva de recursos naturais nele presentes; 
disponibilidade de recursos financeiros, formas e tempo necessários para gerá-los, a fim de adquirir produtos manufaturados; e decisão sobre a escala requerida para tais produtos bem como o comando sobre os canais tradicionais de distribuição e circulação dos recursos. Em outras palavras, o autor ressalta que os indígenas precisariam de recursos financeiros para adquirir produtos e serviços sob o monopólio de não-indígenas a fim de implantar seus projetos de etnodesenvolvimento. Então, segundo a "[...] vocação histórica e cultural específica da sociedade indígena e do controle interno do tempo para a produção para o mercado [...]" essa poderia estabelecer os limites para a sua produção, alterando, assim, também suas necessidades externas (Azanha, 2002, p. 35).

Nesse cenário, o papel do Estado seria o de não mais tutelar o indígena, mas o de amparar o etnodesenvolvimento num sistema globalizado, balizado pela história, valores, interesses e objetivos endógenos, os quais imprimiriam a marca política, econômica e simbólica indígena em meio ao auxílio de atores diversos, tais como, entidades indígenas, agências bilaterais, organizações do terceiro setor, agências governamentais indigenistas e ambientalistas (Verdum, 2002).

Diferente do etnodesenvolvimento, o Sumak Kawsay e o Suma Qamaña - propostas indianistas surgidas na realidade latino-americana no início do século XXI - se manifestaram em oposição ao colonialismo e ao neoliberalismo no contexto de crises econômicas, sociais e políticas, durante os processos constituintes do Equador e da Bolívia, e se espraiaram pela América Latina e pela Europa (Torres-Solis \& Ramírez-Valverde, 2019).

O Sumak Kawsay é um conceito original vindo da cosmologia indígena, o qual se traduz em princípios de vida e plenitude que funcionam como guias para a ação, relacionados à harmonia com a natureza, com o cosmos, com a vida, com a história e com todas as formas de existência. Noções aproximadas são encontradas entre os povos Aymara (Suma Qamaña), Guarani (Ñandereko), Ashuar (Shiir waras) e Mapuche (Küme Mongen) (Vanhulst \& Beling, 2013). Após seu espalhamento, surgiram diferentes vertentes do bem viver, tais como, a socialista-estatista, a ecologista/pós-desenvolvimentista e a indigenista/"pachamamista" (Torres-Solis \& Ramírez-Valverde, 2019).

A base de informação para o bem viver socialista/estatista, segundo Gallegos (2010), fundamenta-se não somente no ter, mas no ser, estar, fazer e sentir, isto é, no viver a plenitude ou bem viver. Nesse sentido, o bem viver ou o viver bem se referem " [...] à satisfação de necessidades, à consecução de uma qualidade de vida e morte dignas, ao amar e ser amado e ao florescimento saudável de todos, em paz e harmonia com a natureza, para a prolongação das culturas humanas e da biodiversidade" (Gallegos, 2010, p. 61). O mesmo autor aponta, ainda, que o alcance de tais patamares de satisfação supõem a existência de tempo livre para que se busque a contemplação e a emancipação, de modo que, para o desenvolvimento dos indivíduos e coletivos, outros requisitos devem ser atendidos, tais como, liberdades, oportunidades, capacidades e potencialidades reais, os quais são exercidos sem dominação sobre o outro, o que possibilitaria a construção do reconhecimento mútuo, da autorrealização e da realização de um porvir social compartilhado.

Já a vertente ecologista/pós-desenvolvimentista enfoca o bem viver na perspectiva da Mãe Terra, alternativamente ao modelo de desenvolvimento extrativista e capitalista. Isso significa a resistência por parte dos indígenas e dos campesinos ao avanço da degradação e da contaminação do solo e da água, a luta contra a entrada de transgênicos em seus territórios e cultivos, contra privatização da água e, por outro lado, a busca de se ter o suficiente para comer, não por meio de supermercados, mas pela presença de condições de produção do que desejam, ou seja, ter o comando sobre territórios (não apenas terra), água, sementes, estradas, organização política própria, educação e sistema de saúde próprios; em outras palavras, condições de vida globais e diversas as quais se confundem entre direitos da Mãe Terra e o dos povos (Molina; Paty \& Lopez, 2012).

Na concepção indigenista/“pachamamista”, Hidalgo-Capitán; Arias e Ávila (2014) indicam algumas dimensões para a realização do Sumak Kawsay, como: 1) a existência de um território tal qual um cosmo vital com três esferas, a roça, a floresta e a água, as quais se relacionam com elementos materiais e simbólicos; 2) o entendimento de que os elementos imprescindíveis 
para o bem viver serão obtidos junto a natureza mediante o desenvolvimento de qualidades (força, equilíbrio, sabedoria, compreensão, visão, perseverança e compaixão), em processo de aprendizagem comunitária; 3) a presença de uma dimensão ética em que estão inclusos diversos valores de harmonia doméstica; e 4) a busca da harmonia em todos os lugares para haver harmonia na comunidade, o que requer solidariedade, manifesta em respeito e valorização de anciãos e viúvas e no compartilhamento e reciprocidade entre os membros da comunidade.

Uma grande novidade inserida na vertente pachamamista são os direitos próprios da natureza, os quais se encontram constitucionalizados no Equador. A natureza tem o direito de ser respeitada integralmente, tornando possível a manutenção e a regeneração de seus ciclos vitais, estruturais, funcionais e processos evolutivos, de modo que qualquer pessoa, comunidade, povo ou nacionalidade poderá requerer que as autoridades públicas respeitem tais direitos e que o Estado fomente pessoas físicas e jurídicas nesse sentido (Gudynas, 2009).

Mamani (2010) aponta que no bem viver há uma identidade cultural que surge de um processo de relação profunda com o lugar onde se vive, no qual emergem modos de vida, expressões, tais como, arte, dança, música, vestimenta, etc., os quais são vivenciados nesse ambiente. $\mathrm{O}$ conceito identidade remete à historicidade, viver o momento presente a partir de uma memória, de uma ancestralidade, o que sugere uma perspectiva de futuro que, além de ser vivida, pode ser possível. Com isso, percebe-se que a visão de mundo dos segmentos marginalizados pela história, precisamente dos povos originários, é uma possibilidade para construir novos tipos de sociedades, embasadas pelo bem conviver em comunidade e com a natureza (Acosta, 2016).

Nessa perspectiva, o bem viver coloca em xeque o padrão produtivista e consumista como referência que dicotomiza a organização da sociedade. A grande importância do bem viver diante da sociedade dicotomizada é a de revelar a existência de aprendizados, mesmo que esses modos de vidas não estejam vinculados ao processo de modernidade, os quais podem fazer repensar o próprio conceito de desenvolvimento e progresso (Mamani, 2010).

Para Acosta (2016), a proposta de harmonia com a natureza, reciprocidade, relacionalidade, complementaridade e solidariedade entre os indivíduos e comunidades, posiciona-se exatamente contrária ao conceito de acumulação perpétua. Assim, estabelece uma proposta e uma oportunidade para refletir sobre outra realidade de vida, na qual os indivíduos formam parte de um todo mais harmônico com a natureza e com os outros indivíduos, tendo em consideração a alteridade (De La Cuadra, 2015).

O bem viver pode também ser visualizado como um paradigma que orienta as políticas públicas e ações dos Estados Nacionais na regulação de relações sociais, sob o propósito de reduzir as desigualdades na sociedade e melhorar as condições de vida dos sujeitos em situação de vulnerabilidade econômica. Por fim, o diálogo gerado sobre o bem viver sugere repensar a própria definição de desenvolvimento, relativizando-o a partir do entendimento de interculturalidade e do desenvolvimento etnicamente sensível.

\subsection{Implicações do etnodesenvolvimento e bem viver indígena nas políticas públicas}

Deve-se ter em conta que a interculturalidade é primordial na (re)construção de um pensamento crítico/reflexivo sobre o desenvolvimento e sobre as políticas públicas, mais especificamente por três motivos principais: primeiro, porque pode ser concebida e pensada desde a experiência vivida pelos movimentos indígenas; segundo, porque reflete um pensamento que não é baseado nos legados eurocêntricos ou da modernidade; e terceiro, porque corresponde a identificação da origem no sul, demonstrando, assim, uma mudança na geopolítica do conhecimento cujo centro é o norte global (Walsh, 2009).

Para Walsh (2009), a interculturalidade se insere em uma arena política e conflitiva, na qual transitam lutas históricas, interesses políticos e econômicos, os quais ocasionam tensões e paradoxos de compreensões, usos e projetos de interculturalidade como, 
[...] um projeto que por necessidade convoca a todos os preocupados pelos padrões de poder que mantêm e seguem reproduzindo o racismo, a racionalização, a desumanização de alguns e a sobre-humanização de outros, a subalternização de seres, saberes e formas de viver. Seu projeto é a transformação social e política, a transformação das estruturas de pensar, atuar, sonhar, ser, estar, amar e viver (Walsh, 2009, p. 15).

A interculturalidade e o pós-desenvolvimento assinalam que, na convergência entre o etnodesenvolvimento e as políticas públicas, mantém-se uma base de operacionalismo, traduzida na imposição de uma ideia de desenvolvimento para suprir necessidades, a qual transforma a diversidade cultural não em uma alteridade, mas num critério de eficácia. Também, está presente no modelo de etnodesenvolvimento o economicismo, aparente na coisificação da vida social em aparato econômico apriorístico e transcendente. Além disso, esta alternativa de desenvolvimento carrega um componente institucionalista quando reproduz a participação - compreendida em termos de eficiência (melhores resultados) e empoderamento (poder ou capacidade de um indivíduo ou comunidade obter melhores condições de vida) - como um mecanismo de seleção de certas lideranças capazes de comunicar interesses da modalidade de desenvolvimento vigente como interesses do grupo social representado (Ayala \& Fehlauer, 2005).

Quanto ao bem viver, alguns desafios apresentados são: 1) Evitar sua captação pelo desenvolvimento hegemônico, uma vez que este paradigma não tem como substrato a tradição ocidental cristã, transcendental, e não parte de perspectivas antropocêntricas ou racional-científicas, tendo, por isso, instrumentos para decolonizar o conhecimento; 2) Conceber alternativas de desenvolvimento viáveis em horizontes temporais longos, sem permitir a repetição do ocorrido com o desenvolvimento sustentável, cujas bases filosóficas de solução dos problemas são as mesmas que as causadoras desses (Guevara-Aristizábal \& Eschenhagen, 2017).

Há também desafios da ordem de compreensão dos direitos da natureza. O conceito da Pachamama não compreende a preservação e conservação da natureza em termos exclusivos de sua utilidade para o ser humano, isto é, apenas como extensão de seus direitos de propriedade, os chamados direitos de terceira geração. Os direitos da natureza, no âmbito do bem viver, encerram valores intrínsecos do meio ambiente, os quais rompem com a postura antropocêntrica por serem independentes de valorações humanas (Gudynas, 2009).

Outro aspecto importante no bem viver, que chama atenção frente ao desenvolvimento, é a dimensão metafísica, a qual pode estar em conflito com a racionalidade instrumental e técnico-científica, cujo mote foi sempre o da deslegitimação de outros tipos de saberes. Também nesse sentido, o holismo do bem viver, que contempla o universal e o plural, segue sendo um desafio para o desenvolvimento, porque o holismo preza por uma consciência da espécie humana que envolve a integração do habitat planetário com relações sustentáveis com esse. Esta percepção da alternativa ao desenvolvimento faz emergir tanto uma nova concepção do espaço (topoconsciência) como uma nova concepção do tempo (cronoconsciência), as quais são transcendentes à visão europeizante e eurocêntrica da modernidade, que se pauta pelo individualismo, racionalismo e pragmatismo (Vanhulst \& Beling, 2013).

Somam-se a esses desafios, o fato de o bem viver impor mudanças radicais, e não apenas incrementais como pressupõem os diversos paradigmas de desenvolvimento sustentável. O bem viver reclama transformações nas estruturas econômicas e nas relações de poder inter e intrasocialmente (Vanhulst \& Beling, 2013). É natural do discurso do bem viver o afastamento da ideia de homogeneidade cultural e social, o que pode significar aproximações desta concepção que correspondem com as modernas teorias pluralistas ou que se aproximam mais da ideia essencialista e particularista do próprio buen vivir (Vanhulst, 2015).

\section{Conclusão}

O esgotamento do desenvolvimento hegemônico criou oportunidades para que fossem pensadas alternativas aos 
modelos desenvolvimentistas até então vigentes. São apresentados neste artigo um desenvolvimento alternativo específico, o etnodesenvolvimento, e uma alternativa ao desenvolvimento também específica, o bem viver. Ambos têm como foco ou ponto de partida as realidades indígenas da América Latina.

Ao discorrer sobre o desenvolvimento em sua interface com as políticas públicas, percebe-se que o desenvolvimento como liberdade, teoria do economista Amartya Sen, pode ser compatibilizado com o modo de vida indígena e, ainda assim, promover o modo de vida desejado por essa população, se são compreendidas suas concepções de bem-estar e se essas são eficazmente traduzidas no âmbito das políticas públicas.

Para a verificação dessa clivagem do desenvolvimento como fenômeno endogenamente emergente e etnicamente sensível, há vários modelos de análise de políticas públicas, os quais podem ser, inclusive, utilizados em conjunto. Isso significa que problemas e soluções a partir de perspectivas étnicas poderão ser considerados quanto a uma variedade de lentes teóricas e instrumentais analíticos a fim de se conhecer quem ganha o quê, quando e como nas políticas públicas.

A ótica indianista do bem-estar pode, nesse sentido, tanto estar mais alinhada com os processos de desenvolvimento centrado histórica e culturalmente no etnodesenvolvimento, neste caso, sem abrir mão do economicismo capitalista, ou pode contrapor completamente todas as influências exógenas de modos de vida que não lhe apeteçam, dado que partem de uma lógica eurocêntrica, ao escolher o bem viver.

O bem viver pode parecer imensamente mais interessante do que o etnodesenvolvimento porque não é uma adaptação do desenvolvimento capitalista aos traços culturais originários, como é o caso do etnodesenvolvimento. Porém, o bem viver se encontra muito mais distante da viabilidade por seu discurso e prática política serem considerados, em muitos espaços, como mera utopia.

No entanto, a referência ao bem viver como utopia não é inteiramente justa, pois países latino-americanos, como o Equador e a Bolívia, preveem o bem viver em suas constituições, fruto de momentos históricos em que os movimentos sociais indígenas - a população indígena é representativa nesses países - foram capazes de transmitir suas demandas ao nível mais alto de garantias, o do contrato social do Estado Nacional.

Obviamente, como direcionador para a alocação de valores, tanto o etnodesenvolvimento como o bem viver enfrentariam muitos desafios para serem implementados em um país como o Brasil, já que os conflitos entre atores, bens e serviços sociais e custos políticos se uniriam às dificuldades intrínsecas dos paradigmas adotados, no quais as decisões são centralizadas na compreensão indígena do mundo, de forma que a negociação para o sucesso da política pública em tais modelos de desenvolvimento se tornaria necessária de ser exercido árdua e continuamente.

Diante disso, fica colocada a necessidade de que novas pesquisas sejam implementadas no sentido de aferir a endogeneidade das ideias de desenvolvimento e a participação de indígenas em fluxos de políticas públicas cujos resultados digam respeito a este estrato da população. Nesse sentido, tanto o ambiente em que se processam políticas públicas como as ideias imbuídas nas diferentes etapas de seu processamento se mostram como espaços interessantes de análise.

\section{Referências}

Acosta, A. (2016). O bem viver: uma oportunidade para imaginar outros mundos: Autonomia Literária/Elefante.

Acosta, L. E., Mendoza, D., De La Cruz, P. E., \& Murcia, U. G. (2020). Indicadores de Bienestar Humano Indígena (IBHI). Primer reporte sobre el estado de los modos de vida y territórios de los pueblos indígenas del departamento de Amazonas. Colombia: Instituto Amazónico de Investigaciones Científicas-Sinchi.

Almeida, A. W. B. Apresentação. (2007). In: Shiraishi Neto, J. (Org.). Direito dos povos e comunidades tradicionais no Brasil: declarações, convenções internacionais e dispositivos jurídicos definidores de uma política nacional: UEA.

Azanha, G. (2002). Etnodesenvolvimento, mercado e mecanismos de fomento: possibilidades de desenvolvimento sustentado para as sociedades indígenas no Brasil. In Lima, A. C. S., \& Barroso-Hoffmann, M. Etnodesenvolvimento e políticas públicas: bases para uma nova política indigenista: Contracapa. 
Ayala, C., \& Fehlauer, T. (2005). Considerações críticas sobre o conceito etnodesenvolvimento: para pensar a condescendência na relação intercultural. Tellus, 5(8/9), 37-51. http://dx.doi.org/10.20435/tellus.v0i8/9.94

Batalla, G. B. (1982). El etnodesarrollo: sus premisas jurídicas, políticas y de organización. In Aravena, F. R. América Latina: etnodesarrollo y etnocidio: Ediciones Flacso.

Castro, J. A., \& Oliveira, M. G. (2014). Políticas públicas e desenvolvimento. In Madeira, L. M. (organizadora). Avaliação de políticas públicas: UFRGS/CEGOV

Creswell, J. W. (2007). Projeto de pesquisa: métodos qualitativo, quantitativo e misto: Artmed.

De La Cuadra, F. de. (2015). Buen Vivir: ¿Una auténtica alternativa post-capitalista? Polis, 14(40). http://journals.openedition.org/polis/10893

Dye, T. R. (2014). Mapeamento dos modelos de análise de políticas públicas. In Heidemann, F. G., Salm, J. F. (Organizadores). Políticas públicas e desenvolvimento: bases epistemológicas e modelos de análise. Brasília-DF, Editora Universidade de Brasília.

Escobar, A. (2014). Sentipensar con la tierra. Nuevas lecturas sobre desarrollo, territorio y diferencias: Ediciones Unaula.

Ferrari, R. (2015). Writing narrative style literature reviews. Medical Writing, 24(4), 230-235. 10.1179/2047480615Z.000000000329

Florit, L. F. (2016). Conflitos ambientais, desenvolvimento no território e conflitos de valoração: considerações para uma ética ambiental com equidade social. Desenvolvimento e Meio Ambiente, 36(1), 255-271: http://dx.doi.org/10.5380/dma.v36i0.41624

Gallegos, R. R. (2010). Socialismo del sumak kawsay o biosocialismo republicano. In Secretaría Nacional de Planificación y Desarrollo-Senplades. Los nuevos retos de América Latina: Socialismo y sumak kawsay: Senplades.

Gil, A. C. (2002). Como elaborar projetos de pesquisa. (4a ed.): Atlas.

Guevara-Aristizábal J. F., \& Eschenhagen, M. L. (2017). Pensar em tempos de crisis: ¿como dialogar com la vida? Nómadas, 46(1), 237-250. http://www.scielo.org.co/pdf/noma/n46/0121-7550-noma-46-00237.pdf

Gudynas, E. (2009). La ecología política del giro biocéntrico en la nueva Constitución de Ecuador. Revista de Estudios Sociales, 32(1), 34-47. http://www.scielo.org.co/pdf/res/n32/n32a03.pdf

Gudynas, E. (2004). Valores y etica ambiental. In Gudynas, E. Ecología, economía y etica del desarrollo sostenible: Coscoroba Ediciones.

Heidemann, F. G. (2014). Do sonho de progresso às políticas de desenvolvimento. In Heidemann, F. G., \& Salm, J. F. (Organizadores). Políticas públicas e desenvolvimento: bases epistemológicas e modelos de análise: Editora Universidade de Brasília.

Hidalgo-Capitán, A. L., Arias, A., \& Ávila, J. (2014). El pensamiento indigenista ecuatoriano sobre el Sumak Kawsay. In Hidalgo-Capitán, A. L., García, A. G., \& Guazha, N. D (Editores). Sumak Kawsay Yuyay. Antología del pensamiento indigenista ecuatoriano sobre Sumak Kawsay. Huelva-España, Cuenca: Ecuador: Agencia Andaluza de Cooperación Internacional para el Desarollo.

Howlett, M., Ramesh, M. \& Perl, A. (2013). Políticas públicas: seus ciclos e subsistemas: uma abordagem integradora: Elsevier.

Mamani, F. H. (2010). Buen vivir/vivir bien. Filosofía, políticas, estrategias y experiencias regionales andinas. Lima-Perú: Oxfam América y Solidaridad Suecia América Latina.

Molina, M. C., Paty, M. R., \& López, E. (2012). La construcción del Suma Qamaña. América Latina en movimiento, 479(1), 18-21. https://www.alainet.org/sites/default/files/alai479w.pdf

Pereira, A. S., Shitsuka, D. M., Parreira, F. J., \& Shitsuka, R. (2018). Metodologia da Pesquisa Científica. UAB/NTE/UFSM.

Rodrigues, M. M. A. (2015). Políticas públicas: Publifolha.

Rua, M. G. (1998). Análise de políticas públicas: conceitos básicos. In Rua, M. G. \& Valladão, M. I. C. O estudo da política: tópicos selecionados: Paralelo 15 .

Sachs, I. (2009). Prefácio: ecodesenvolvimento e justiça social no Brasil. In Pádua, J. A. (Organizador). Desenvolvimento, justiça e meio ambiente: Editora UFMG; Editora Peirópolis.

Secchi, L. (2013). Políticas públicas: conceitos, esquemas de análise, casos práticos: Cengage Learning.

Secchi, L. (2016). Análise de políticas públicas: diagnóstico de problemas, recomendação de soluções: Cengage Learning.

Sen, A. (2010). Desenvolvimento como liberdade: Companhia das Letras.

Stavenhagen, R. (2013). Ethnodevelopment: a neglected dimension in development thinking (1986). In Stavenhagen, R. Pioneer on Indigenous Rights: Springer.

Torres-Solis, M., \& Ramírez-Valverde, B. (2019). Buen vivir y vivir bien: alternativas al desarrollo en Latinoamérica. Latinoamérica. Revista de Estudios Latinoamericanos, 69(1), 71-97. https://doi.org/10.22201/cialc.24486914e.2019.69.57106

Vanhulst, J. (2015). El laberinto de los discursos del Buen vivir: entre Sumak Kawsay y Socialismo del siglo XXI. Revista Latinoamericana, 14(40), 233-261. https://journals.openedition.org/polis/10727 
Research, Society and Development, v. 10, n. 2, e48910212860, 2021

(CC BY 4.0) | ISSN 2525-3409 | DOI: http://dx.doi.org/10.33448/rsd-v10i2.12860

Vanhulst, J., \& Beling, A. (2013). El buen vivir: una utopía latinoamericana en el campo discursivo global de la sustentabilidad. Polis, Revista Latinoamericana, 12(36), 497-522. https://journals.openedition.org/polis/9638

Verdum, R. (2002). Etnodesenvolvimento e mecanismos de fomento do desenvolvimento dos povos indígenas. a contribuição do subprograma Projetos Demonstrativos (PDA). In Lima, A. C. S., \& Barroso-Hoffmann, M. Etnodesenvolvimento e políticas públicas: bases para uma nova política indigenista: Contracapa.

Walsh, C. (2009). Interculturalidad, estado, sociedad. Luchas (de) coloniales de nuestra epoca: Universidad Andina Simón Bolívar e Abya-Yala. 